Case Report

\title{
Renal Artery Thrombosis: A Post COVID-19 Sequel
}

\author{
Shrikant B Deshmukh', Kavita M Upadhyay', Advait Kulkarni ${ }^{3}$, Sudhir Deshpande ${ }^{4}$, \\ $\underline{\text { Rajshri Purohit }}^{5}$, Milind Kulkarni ${ }^{6}$
}

${ }^{1}$ M.D. (Medicine), DNB Nephrology, Consultant Department of Nephrology, Dr. Hedgewar Hospital, Aurangabad, Maharashtra, India.

2,3M.B.B.S., Resident DNB General Medicine, Dr. Hedgewar Hospital, Aurangabad, Maharashtra, India.

4,6M.B.B.S, D.A, Intensivist, Dr. Hedgewar Hospital, Aurangabad, Maharashtra, India.

${ }^{5}$ M.S. (General Surgery), Dr. Hedgewar Hospital, Aurangabad, Maharashtra, India.

DOI: https://doi.org/10.24321/2349.7181.202009

\section{I $\quad \mathbf{N} \quad \mathbf{F} \quad \mathbf{O}$}

\section{Corresponding Author:}

Kavita M Upadhyay, Dr. Hedgewar Hospital, Aurangabad, Maharashtra, India.

E-mail Id:

kavita3194@rediffmail.com

Orcid Id:

https://orcid.org/0000-0002-7111-6671

How to cite this article:

Deshmukh SB, Upadhyay KM, Kulkarni A, Deshpande S, Purohit R, Kulkarni M. Renal Artery Thrombosis: A Post COVID-19 Sequel. J Adv Res Med 2020; 7(2): 22-24.

Date of Submission: 2020-11-21

Date of Acceptance: 2020-12-05

\section{$\begin{array}{llllllll}\mathbf{A} & \mathbf{B} & \mathbf{S} & \mathbf{T} & \mathbf{R} & \mathbf{A} & \mathbf{C} & \mathbf{T}\end{array}$}

Since the outbreak of the COVID-19 pandemic, increasing evidence suggests that infected patients present a high incidence of thrombotic complications. Besides affecting respiratory tract it also causes systemic inflammation which also leads to coagulopathy affecting major blood vessels in the body. This report describes a case of aortic, renal artery thrombosis in a patient admitted for evaluation of abdominal pain and detected to have high titer of SARS COV-2 IgG antibodies with no prior history suggestive of typical COVID-19 infection (COVID-19 RTPCR and antigen tested negative).

Keywords: COVID-19, IgG SARS CoV-2, Renal Artery Thrombosis

\section{Introduction}

COVID-19 infection has spread all over the globe and has infected more than 3 crores of peoples. Various researches have given increasing evidence of high incidence of thrombotic complications such as deep vein thrombosis, ${ }^{1}$ pulmonary embolism, ${ }^{2}$ or micro vascular thrombosis in infected patients. ${ }^{3}$ Recent studies ${ }^{4,5}$ have found out hypercoaguable state in the COVID patients supposedly consequences of inflammatory storm during the infection. There is evidence of raised inflammatory markers like IL-6 along with coagulation markers like D-dimer. This hypercoagulability induced by COVID-19 seems to be responsible for venous thromboembolic events but can also cause arterial complications. ${ }^{6}$ We report a case of patient presenting with arterial thrombosis as a sequel of COVID-19 infection. In absence of typical COVID-19 symptoms we must have a high index of suspicion for early recognition of vascular complications in the patients.

\section{Case}

A 55 year old female had pain in abdomen since 3 days. This was associated with intermittent episodes of vomiting. She was hemodynamically stabilized and was further investigated with routine blood investigations and radiological imaging. 
Table I.laboratory investigation

\begin{tabular}{|c|c|c|}
\hline Investigations & Reports & Reference \\
\hline Total Leukocyte count (/uL) & 19600 & $4-10$ \\
\hline Neutrophil (\%) & 88 & $40-80$ \\
\hline Lymphocytes (\%) & 5 & $20-40$ \\
\hline Platelet (/uL) & 220000 & $150-410$ \\
\hline Hemoglobin g/dL & 15.2 & $11-15$ \\
\hline Prothrombin time $(\mathrm{s})$ & 14.3 & $11-16$ \\
\hline $\begin{array}{c}\text { Activated Partial } \\
\text { thromboplastin time (aPTT) (s) }\end{array}$ & 34 & $30-40$ \\
\hline D-dimer (microgram/ml) & 5.19 & $0-0.5$ \\
\hline Cardiac troponin I (pg/ml) & 398 & $0-17.9$ \\
\hline Protein C (IU/dL) & 74 & $65-135$ \\
\hline Protein S (\%) & 62 & $70-140 \%$ \\
\hline Anti-thrombin III (\%) & 85 & $80-130 \%$ \\
\hline e-GFR $(\mathrm{ml} / \mathrm{min} / 1.73 \mathrm{~m} 2)$ & 24 & \\
\hline Procalcitonin (ng/ml) & 5.43 & $0-0.5$ \\
\hline Amylase (U/L) & 38.7 & $0-90$ \\
\hline Lipase (U/L) & 14 & $0-67$ \\
\hline SARS Cov 2 antibody & Positive & \\
\hline COVID-19 antigen & Negative & \\
\hline COVID-19 RT PCR & Negative & \\
\hline
\end{tabular}

She was diagnosed to have inflamed appendix on plain CT scan of abdomen which was confirmed by histopathology after appendectomy. Despite surgery she had persistent pain in abdomen which was not relieved by analgesic medications. Therefore a contrast enhanced CT scan of abdomen and pelvis was done.The scan reported an extensive thrombus from abdominal aorta involving both renal arteries. She eventually developed multi organ dysfunction and sepsis.

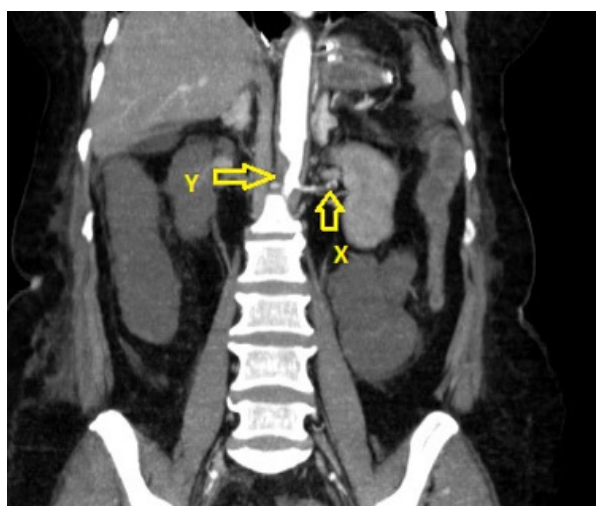

Image I.CECT Abdomen Coronal section showing

X-Partial thrombosis of left renal artery, Y-Partial Aortic thrombus and thrombosis of right renal artery

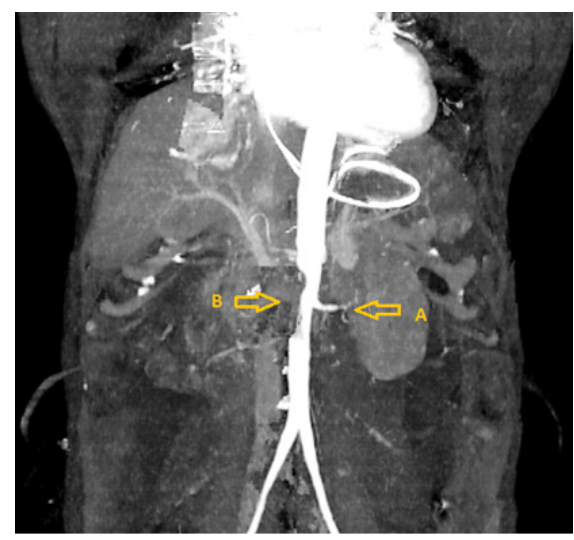

Image 2.CECT abdomen Reconstructed image showing A - Partial thrombosis of left renal artery, B- Partial Aortic thrombus and thrombosis of right renal artery

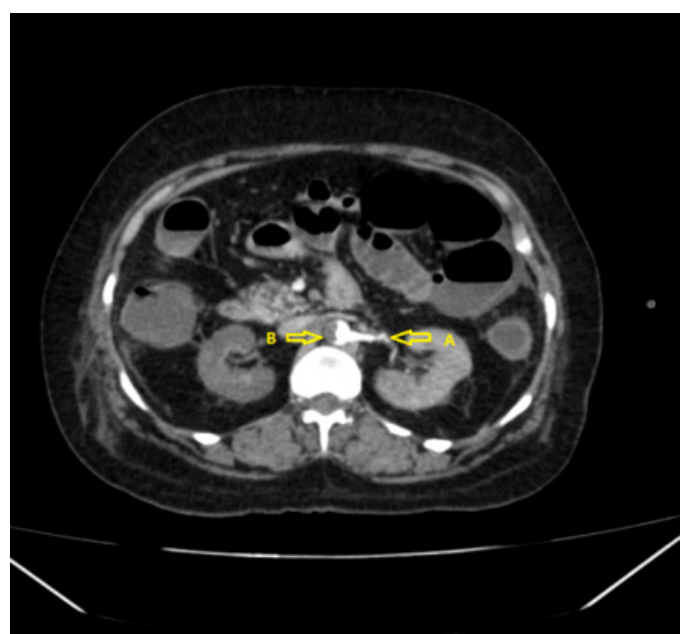

Image 3.CECT abdomen axial section showing $A$ : Partial thrombosis of left renal artery, B: Partial Aortic thrombus

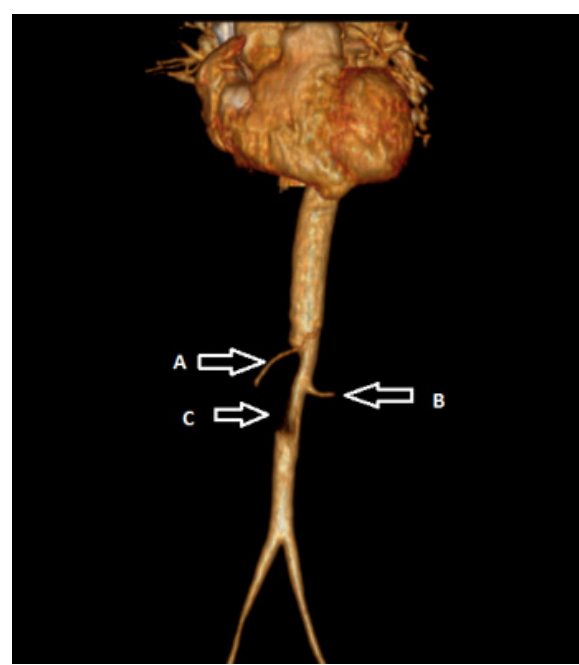

Image 4.CECT Abdomen 3D reconstructed image showing A - superior mesenteric artery, B-: Partial thrombosis of left renal artery, C- Partial Aortic thrombus and non visualization of right renal artery due to thrombosis 


\section{Discussion}

As we continue to learn more about the COVID-19 virus and study clinical outcomes of infected patients, our knowledge of its complications and preparedness for their onset will subsequently improve. Many authors have recently demonstrated a strong link between COVID-19 infection and thromboembolism. In our case we observed that patient had no any clinical symptoms suggestive of typical COVID-19 infection ${ }^{7}$ and primary event went unnoticed. On evaluation her SARSCov-2 antibody-positive and COVID-19 antigen and RTPCR were negative. She was initially diagnosed with appendicitis and underwent appendectomy but persistent post operative abdominal pain necessitated further evaluation. An extensive thrombus from abdominal aorta involving both renal arteries was found on repeat contrast CT scan of abdomen. On further evaluated for hypercoagulable state (protein C and S, anti-thrombin, factor - V Leiden) no serological abnormalities were detected. A recent study by Bikdeli B et al. attributes post COVID-19 infection sequele to excessive inflammation, platelet activation, endothelial dysfunction and stasis. ${ }^{8}$ Spiezia L et al have suggested that formation and polymerization of fibrin are responsible for this hypercoagulability. ${ }^{9}$ Many recent recommendations have therefore insisted on prophylactic measures to prevent thromboembolism (10-12). A recent study by Varga Z et al. observed evidence of the presence of virus in endothelial cells. ${ }^{13}$ This could be possible due to wide expression of angiotensin-converting enzyme-2 receptor (virus uses this receptor to infect cells) in endothelial cells eventually leading to endothelitis, venous and arterial thrombosis. In present scenario, patient presenting with extensive thrombosis, need evaluation for COVID-19 status even in absence of primary symptoms.

\section{Conclusion}

COVID-19 infection can lead to vascular thrombosis in symptomatic as well as asymptomatic patients. This case report adds to the knowledge about consequences of COVID-19 infection.

\section{Conflict of Interest: None}

\section{References}

1. Llitjos JF, Leclerc M, Chochois C, Monsallier JM, Ramakers M, Auvray M et al. High incidence of venous thromboembolic events in anticoagulated severe COVID-19 patients. J Thromb Haemost 2020.

2. Fabre O, Rebet O, Carjaliu I, Radutoiu M, Gautier L, Hysi I. Severe Acute Proximal Pulmonary Embolism and COVID-19: A Word of Caution. Ann Thorac Surg 2020.

3. Zhang T, Sun LX, Feng RE. [Comparison of clinical and pathological features between severe acute respiratory syndrome and coronavirus disease 2019]. Zhonghua Jie He He Hu Xi Za Zhi. 2020.
4. Chauhan AJ, Wiffen LJ, Brown TP. COVID-19: A collision of complement, coagulation and inflammatory pathways. Journal of Thrombosis and Haemostasis 2020.

5. Onkarappa Mangala Y, Daid SS, Lakshmanan S, Kapil R, Miskovsky J. Acute Pulmonary Embolism in COVID-19: A Report of Two Cases. Cureus 2020.

6. Klok FA, Kruip MJHA, van der Meer NJM, Arbous MS, Gommers DAMPJ, Kant KM et al. Incidence of thrombotic complications in critically ill ICU patients with COVID-19. Thromb Res 2020.

7. CDC. Symptoms of Coronavirus (COVID-19). Cdc 2020.

8. Bikdeli B, Madhavan MV, Jimenez D, Chuich T, Dreyfus I, Driggin E et al. COVID-19 and Thrombotic or Thromboembolic Disease: Implications for Prevention, Antithrombotic Therapy, and Follow-Up: JACC Stateof-the-Art Review. Journal of the American College of Cardiology 2020.

9. Spiezia L, Boscolo A, Poletto F, Cerruti L, Tiberio I, Campello E et al. COVID-19-Related Severe Hypercoagulability in Patients Admitted to Intensive Care Unit for Acute Respiratory Failure. Thromb Haemost 2020.

10. Barrett CD, Moore HB, Yaffe MB, Moore EE. ISTH interim guidance on recognition and management of coagulopathy in COVID-19: A comment. Journal of Thrombosis and Haemostasis 2020.

11. AK, KGK, ED, GP, GSS, KS et al. Thromboembolic risk and anticoagulant therapy in COVID-19 patients: emerging evidence and call for action. Br J Haematol 2020.

12. Zhai Z, Li C, Chen Y, Gerotziafas G, Zhang Z, Wan J et al. Prevention and Treatment of Venous Thromboembolism Associated with Coronavirus Disease 2019 Infection: A Consensus Statement before Guidelines. Thrombosis and Haemostasis 2020.

13. Varga Z, Flammer AJ, Steiger $P$, Haberecker $M$, Andermatt R, Zinkernagel AS et al. Endothelial cell infection and endotheliitis in COVID-19. The Lancet 2020. 